\title{
Study of maternal mortality trends: 10 years retrospective and comparative analysis at a tertiary teaching hospital of Gwalior Chambal region
}

\author{
Jyoti Bindal*, Garima Solanki \\ Department of Obstetrics \& Gynaecology, G. R. Medical College, Gwalior, MP, India
}

Received: 05 January 2016

Accepted: 06 February 2016

*Correspondence:

Dr. Jyoti Bindal,

E-mail: drjyotibindal@bindal.me

Copyright: ( $\odot$ the author(s), publisher and licensee Medip Academy. This is an open-access article distributed under the terms of the Creative Commons Attribution Non-Commercial License, which permits unrestricted non-commercial use, distribution, and reproduction in any medium, provided the original work is properly cited.

\begin{abstract}
Background: Maternal death is a preventable calamity. The aim of this study was to analyze the causes of maternal mortality in a tertiary teaching hospital.

Methods: The present study was done at Kamla Raja Hospital, G R Medical College and JA Group of Hospitals, Gwalior. We reviewed the records of antenatal patients admitted from January, 2005 to December, 2015. The records were analyzed for parameters related to maternal mortality. The change in trends and causes of maternal mortality in patients between 2005-2010 was compared with the patients admitted from 2010 to 2014.

Results: During 2005-2009 a total of 28370 antenatal patients were admitted and 27711 live births took place, whereas in 2010-2014 a total 30355 patients were admitted and 29305 live births took place. A total $188(0.66 \%)$ and $251(0.83 \%)$ maternal death took place from 2005-2009 and 2010-2014 respectively. Maternal death was more common in unbooked, low socioeconomic status and illiterate patients. The common causes of maternal death were eclampsia, hemorrhage and anemia.

Conclusions: Delay in seeking emergency obstetric care and not having regular antenatal checkups by pregnant females are the major contributors for maternal mortality. Dedicated obstetric intensive care units at referral centers for prompt and comprehensive care may help in reducing the maternal morbidity and mortality.
\end{abstract}

Keywords: Maternal mortality, Hemorrhage, Hypertensive disorders

\section{INTRODUCTION}

In India approximately 28 million women experience pregnancy and 26 million have live births. ${ }^{1}$ Every year 67000 maternal death occur in India and 1 million newborn babies die each year. ${ }^{2}$

The possible reasons other than medical are different logistic causes, failure in the health care system, lack of transport etc., and apart from these there are many social, cultural and political factors which determine the status of women health during pregnancy. ${ }^{3}$
Maternal death is defined as death of a woman while pregnant or within 42 days of termination of pregnancy irrespective of the duration and site of pregnancy from any cause related to or aggravated by the pregnancy except accidental or incidental causes. ${ }^{4}$

India has observed a decline in MMR, it was 677 in 1980 than reduced to 254 in 2005-2006 and it was 212 in 20072009. National Rural Health Mission and Millennium Development Goal 5 (MDG 5) target to reduce MMR to less than 100 by $2015 .^{5}$ 
The present study was done with the aim of assessing the change in trends of maternal mortality in last 10 years and various other factors responsible for it.

\section{METHODS}

It was a retrospective analysis of patients admitted between Jan 2005-Dec 2014 in the department of Obstetrics \& Gynecology of Kamla Raja Hospital, GR Medical College and JA Group of Hospitals, Gwalior.

Patients who died due to complications of pregnancy, labor or the pureperium were included in the study. Those patients who died within 42 days of termination of pregnancy irrespective of the duration and site of pregnancy and deaths resulting from disease present before or developing during pregnancy were also included in present study. Deaths resulting from causes not related to the pregnancy nor to its complication or management like hepatic failure as a results of cirrhosis, malignancies of breast, gastroenteritis, liver rupture, psoas abscess and death from accidental or incidental causes no way related to pregnancy like death from automobile accident and death from suicide were excluded from the study.

Details of the patients like name, age of patients, date of admission and death, booked or unbooked, presenting complaints and details of antenatal care was recorded.

Obstetrics history including marital status, age of marriage, age at first pregnancy primi or multi, history of previous pregnancy and labour, complication during present pregnancy, past and present medical problems.

A thorough analysis of data collected was done. Information was obtained from case sheets including laboratory investigations and maternal mortality records register.

The available records were reviewed for the parameters like incidence of maternal mortality, factors influencing maternal mortality and causes of maternal mortality.

These parameters of the patients admitted during 20052010 were compared with those of admitted from 20102104 to study the change in trends and factors responsible for maternal mortality.

\section{RESULTS}

During the study period of 2005-2014 there were 58725 deliveries were done in the hospital, of which 57016 live births took place and there were 439 maternal deaths. The data of first five years was compared with later five years for assessing the change in trends.

During 2005-2009, there were a total of 28370 deliveries and 27711 live births, whereas during 2010-2104, there were 30355 deliveries, out of which 29305 live births took place. A total $188(0.66 \%)$ and $251(0.83 \%)$ maternal death took place from 2005-2009 and 20102014 respectively. Maternal mortality rate was 6.78 and 8.56 during 2005-2009 and 2010-2014 respectively.

The distribution of patients as par their age and parity is shown in Table 1.

Table 1: Distribution of maternal mortality between 2005-2009 and 2010-2014 according to age and parity.

\begin{tabular}{|c|c|c|c|}
\hline \multicolumn{2}{|l|}{ Parameters } & $\begin{array}{l}\text { Cases (\%) } \\
(2005-2009)\end{array}$ & $\begin{array}{l}\text { Cases (\%) } \\
(2010-2014)\end{array}$ \\
\hline \multirow{5}{*}{ Age (years) } & $<20$ & 25 (13.29) & $44(17.52)$ \\
\hline & $21-25$ & $76(40.42)$ & $123(49.00)$ \\
\hline & $26-30$ & $49(26.06)$ & $61(23.82)$ \\
\hline & $31-36$ & $30(15.9)$ & $14(5.4)$ \\
\hline & $>36$ & $8(4.2)$ & $9(3.5)$ \\
\hline \multirow{6}{*}{ Parity } & Primi & $60(31.37)$ & $91(36.25)$ \\
\hline & 1 & $45(23.91)$ & $59(23.50)$ \\
\hline & 2 & $30(15.92)$ & 37 (14.74) \\
\hline & 3 & $24(12.71)$ & $27(10.54)$ \\
\hline & 4 & $9(5.3)$ & $17(6.64)$ \\
\hline & $<5$ & $20(10.12)$ & $20(7.81)$ \\
\hline
\end{tabular}

Table 2: Distribution of maternal death according various parameters.

\begin{tabular}{|lll|}
\hline Parameters & $2005-2009$ & $2010-2014$ \\
\hline Referred/Direct & $\begin{array}{l}112(59.6 \%) \\
\text { Direct }\end{array}$ & $\begin{array}{l}134(52.34 \%) \\
\text { Referred }\end{array}$ \\
\hline $\begin{array}{l}\text { Socioeconomic status } \\
\text { (Low) }\end{array}$ & $148(78.73 \%)$ & $190(74.22 \%)$ \\
\hline $\begin{array}{l}\text { Socioeconomic status } \\
\text { (Middle) }\end{array}$ & $40(21.27 \%)$ & $66(25.78 \%)$ \\
\hline Un-booked cases & $182(96.81 \%)$ & $248(98.88 \%)$ \\
\hline Work (Housewives) & $178(94.68 \%)$ & $240(93.75 \%)$ \\
\hline
\end{tabular}

Table 3: Distribution of maternal mortality according to causes.

\begin{tabular}{|lll|}
\hline Causes & $\begin{array}{l}\text { Cases }(\%) \\
2005-2009\end{array}$ & $\begin{array}{l}\text { Cases }(\%) \\
2010-2014\end{array}$ \\
\hline Direct & & \\
\hline Hemorrhage (APH/PPH) & $36(19.1)$ & $44(20.1)$ \\
\hline Eclampsia & $38(20.2)$ & $56(21.87)$ \\
\hline Septic abortion & $21(11.7)$ & $42(16)$ \\
\hline Inversion of uterus & $2(1.06)$ & $2(0.78)$ \\
\hline Rupture of uterus & $8(4.2)$ & $10(3.9)$ \\
\hline Indirect & & \\
\hline Severe anaemia & $44(23.40)$ & $58(22.65)$ \\
\hline Heart Disease & $4(2.12)$ & $2(0.78)$ \\
\hline Hepatic encephalopathy & $10(5.3)$ & $14(5.4)$ \\
\hline Pulmonary embolism & $10(5.3)$ & $19(7.42)$ \\
\hline Aspiration pneumonitis & $8(4.24)$ & $17(6.64)$ \\
\hline Amniotic fluid embolism & $8(4.24)$ & $12(4.6)$ \\
\hline DIC & $9(4.7)$ & $10(5.3)$ \\
\hline
\end{tabular}


The various factors which may have an influence on maternal mortality are shown in Table 2.

Various causes either directly or indirectly responsible for maternal deaths are shown in Table 3.

\section{DISCUSSION}

A Large number of patients are admitted and referred from surrounding districts to Kamla Raja Hospital for deliveries and for the treatment of complication of pregnancy and postpartum phase.

Maternal mortality in present study is increased from 188 in 2005-2009 to 251 in 2010-2014. This may be due to the increased no of referrals during 2010-2014, as our hospital is tertiary level health care centre and Medical College. It is referral centre for primary health centre, district hospitals and private hospitals.

Maternal mortality rate was 6.78 during 2005-2009 and 8.56 between $2010-2014$.

Most deaths occurred in 21-25 years of age group. Thaker et al in their study also found 20-24 years age group as most vulnerable for maternal death. ${ }^{6}$ Our results are also consistent with Rao et al, who found most of the maternal deaths between 21-30 years of age. ${ }^{7}$

Majority of the deaths, $78.7 \%$ during 2005-2009 and $70.2 \%$ during 2010-2104, were in patients of low socioeconomic status. This shows that poor nutritional status, anemia malnourishment, lack of antenatal checkups due to illiteracy and unawareness and are the underlying causes.

Out of total deaths, about $96.81 \%$ patients during 20052009 and $98.88 \%$ patients during 2010-2014 were unbooked. It may be due to various social factors. Similar results were reported by other study. ${ }^{7}$

There was higher mortality in primigravidas, $31.3 \%$ during 2005-2009 and 36.70\% during 2010-2014. This shows that health of primi patients is neglected in our society; possible reasons may be illiteracy, low socioeconomic status and religious beliefs. ${ }^{7}$

In present study maternal death from 2005-2009 was maximum $(42.3 \%)$ in direct cases where as between 2010-2014 maximum number $(55.85 \%)$ of death were referred cases. Over 5 years referral to the higher centers has increased but these cases were brought to the hospital in terminal stage and delay was due to ignorance of the seriousness of the condition.

The major causes which were directly responsible for maternal death were eclampsia, hemorrhage and septic abortion, whereas anemia, hepatic encephalopathy and pulmonary embolism were indirectly responsible for maternal deaths. There was no significant change in the factors and the causes of maternal mortality in last 10 years.

Eclampsia was the single most common cause of maternal mortality. High incidence of eclampsia was may be due to delay in seeking the care and patient reach the hospital very late and remain undiagnosed till delivery. Rao et al also reported hypertension as the most common cause for death. ${ }^{7}$ Sarkar et al also noted the similar findings. ${ }^{8}$

Hemorrhage was another important cause of death in the list. Jayashree et al also reported the similar results. ${ }^{3}$

Severe anemia was responsible for $12.7 \%$ and $15.6 \%$ deaths during 2005-2009 and 2010-2014 respectively. The possible reason may be due to most of the patients reached hospital at terminal stage and for longer time they remained undiagnosed with severe anemia. Many patients were not able to stand the stress of labour.

\section{CONCLUSIONS}

Maternal death can be avoided. Maternal deaths are due to delay in deciding to seek care, delay in reaching the healthcare facility in time and sometime trying household remedies because of religious beliefs. Maternal deaths due to obstetric haemorrhages, hypertensive disorders in pregnancy, severe anaemia, hepatitis, heart disease can be prevented only if antenatal women with high risk factors are motivated for regular timely antenatal care at healthcare facility.

Funding: No funding sources

Conflict of interest: None declared

Ethical approval: The study was approved by the Institutional Ethics Committee

\section{REFERENCES}

1. Satyasri YU, Sukapalli U, Thatavarthi P. Maternal mortality review in a government medical hospital of north coastal Andhra Pradesh based on FBMDR forms of NRHM: one year analysis. Intern J Curr Med Appl Sci. 2015;5(3):174-7.

2. National rural health mission. Operational guidelines on maternal and newborn health. Chapter 2. 2013:150 .

3. Jayashree, Hanamshetty A. A study on maternal mortality-at BRIMS Bidar. Intern J Recent Trends Sci Tech. 2014;13(2):415-7.

4. Abouzahr C, Wardlow T. Maternal mortality in 2000: estimates developed by WHO, UNICEF, UNFPA; WHO, 2003. Geneva, Switzerland.

5. National rural health mission: framework for implementation 2005-2012; New Delhi: Ministry of Health and Family Welfare, Government of India. Available at, nrhm.gov.in/nhm/nrhm-framework-forimplementation.html. Accessed on 19 Nov 2015. 
6. Thaker R, Deliwala K, Jadav MM. Retrospective comparative study of obstetric complications and maternal mortality in registered and unregistered Women at tertiary care hospital. NHL J Med Sci. 2013;2(1):28-35.

7. Rao PVR, Jayanthi P. Maternal mortality: A retrospective study in a tertiary centre. J Evol Med Dent Sci. 2015;4(14):2247-54.

8. Sarkar M, Basak S, Mondal SK, Das S, Roy D, Mandal $\mathbf{J}$ et al. Maternal mortality associated with eclampsia in an Indian medical college: a four year retrospective study. J Med Medical Sci. 2013;4(10):394-8.

Cite this article as: Bindal J, Solanki G. Study of maternal mortality trends: 10 years retrospective and comparative analysis at a tertiary teaching hospital of Gwalior Chambal region. Int J Reprod Contracept Obstet Gynecol 2016;5:730-3. 